\title{
Review of X-43A Return to Flight Activities and Current Status
}

\author{
David E. Reubush ${ }^{1}$, Luat T. Nguyen ${ }^{2}$, and Vincent L. Rausch ${ }^{3}$ \\ NASA Langley Research Center, Hampton, VA
}

\begin{abstract}
This paper provides an overview and status of the return to flight activities for the X-43A scramjet flight demonstrator after the first flight mishap. The first flight was attempted on June 2, 2001 and resulted in vehicle destruction by range safety when the booster went out of control early in the flight. In the time since the mishap much work has been done to examine the causes of the failure and make modifications to the booster to insure that the boost for the second flight will be successful. In addition, all other aspects of the flight have been examined to maximize the probability of a successful flight.
\end{abstract}

\section{INTRODUCTION}

The development of reusable launch vehicles holds great promise as the key to unlocking the vast potential of space for business exploitation. Only when access to space is assured with a system which provides routine access with affordable cost will businesses be willing to take the risks and make the investments necessary to realize this great potential. One of the limiting factors in potential cost reductions for chemical rockets is the $\mathrm{I}_{\mathrm{sp}}$ limit.

The use of airbreathing engines holds potential for very significant increases in Isp which could result in a significantly lower cost per pound to orbit (figure 1). Work done in the 1980s and 1990s resulted in a significant number of technologies which only await demonstration before they will begin to be accepted for use in future aerospace vehicles. Key among these technologies is airbreathing engines for hypersonic flight. The materials and design methods for scramjet (supersonic combustion ramjet) engines have been brought to the point that efficient engines and practical vehicles which use them can be developed. One of the major requirements to have these technologies accepted is a flight demonstration. NASA initiated the Hyper-X program (reference 1) to demonstrate that scramjet engines can be designed, constructed, and will operate at the high $\mathrm{I}_{\mathrm{sp}}$ levels necessary for use in access to space vehicles as an initial step to

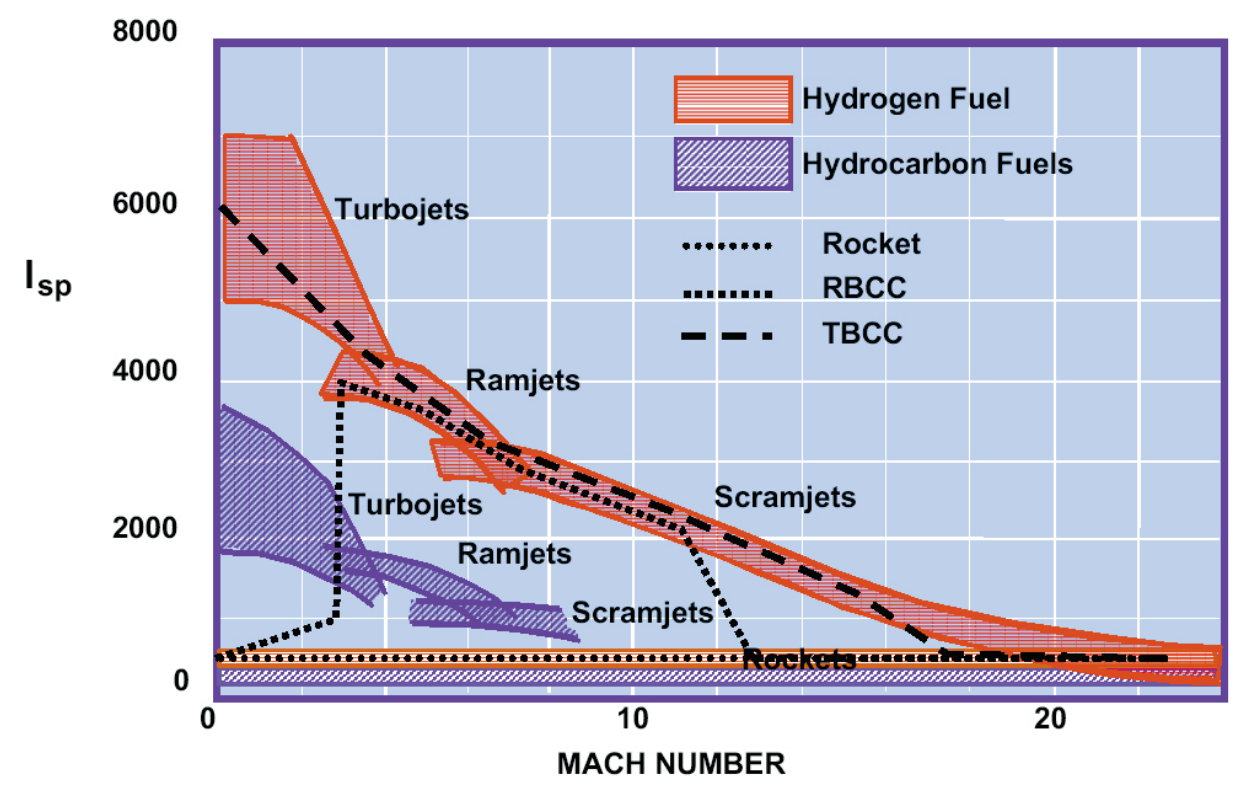

Figure 1. Comparison of Isp for Rockets and Airbreathing Engines

'Deputy Manager, Associate Fellow, AIAA ${ }^{2}$ Return to Flight Manager, Associate Fellow, AIAA ${ }^{3}$ Manager, nonmember, AIAA: NGLT-Flight Vehicles and Systems Program Office, NASA Langley Research Center 
GOALS: Demonstrate, validate and advance the technology, experimental techniques, and computational methods and tools for design and performance predictions of a hypersonic aircraft powered with an airframe-integrated, scramjet engine

\section{FLIGHT OBJECTIVES:}

- Free-flight demonstrations

(Two@ Mach 7, one @ Mach 10)

- Methods verification

- Scaling confirmation

Primary Metric: Accelerate

\section{TECHNOLOGY OBJECTIVES:}

- Vehicle design \& risk reduction

- Flight validation of design methods

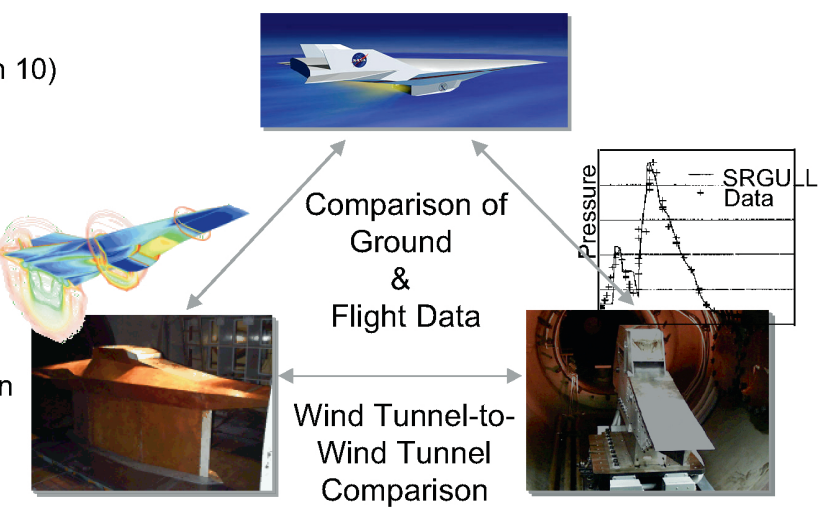

- Design method enhancement

- Hyper-X Phase 2 and beyond

Figure 2. Goals and Objectives of the Hyper-X Program

this end as well as to validate the design tools and methods to be used in the development of future hypersonic vehicles (figure 2).

The NASA Hyper-X program employs a low cost approach to design, build, and flight test three small, airframe-integrated scramjet powered research vehicles (figure 3) at Mach numbers of 7 and 10. The research vehicles will be dropped from the NASA Dryden B-52, rocket boosted to test point by a Pegasus first stage motor, separated from the booster, and then the scramjet powered vehicle operated in autonomous flight (figures 4 and 5). Tests will be conducted at approximately $100,000 \mathrm{ft}$. (depends on Mach number) at a dynamic pressure of about 1000 psf. The first Mach 7 flight was attempted on June 2, 2001. This flight ended in failure when the Pegasus booster went out of control early in the flight and had to be destroyed by range safety. This

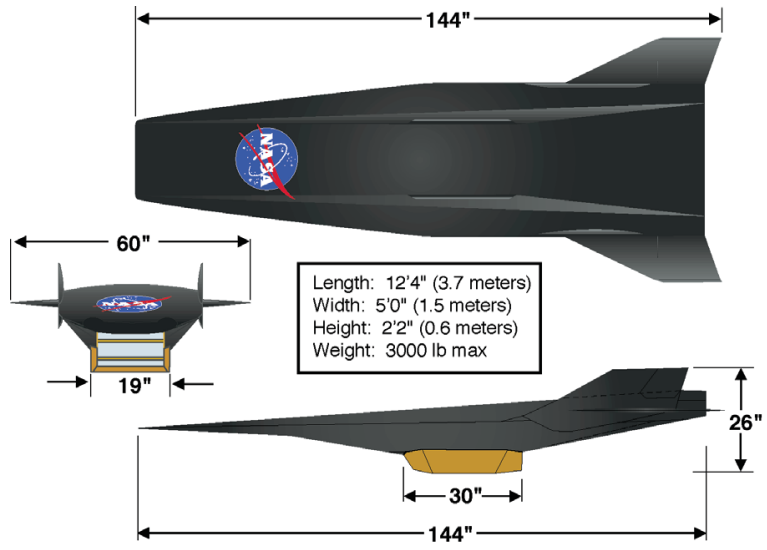

Figure 3. X-43A Vehicle Geometry paper will discuss the work done to recover from the first flight failure and to maximize the probability of success of the second Mach 7 flight.

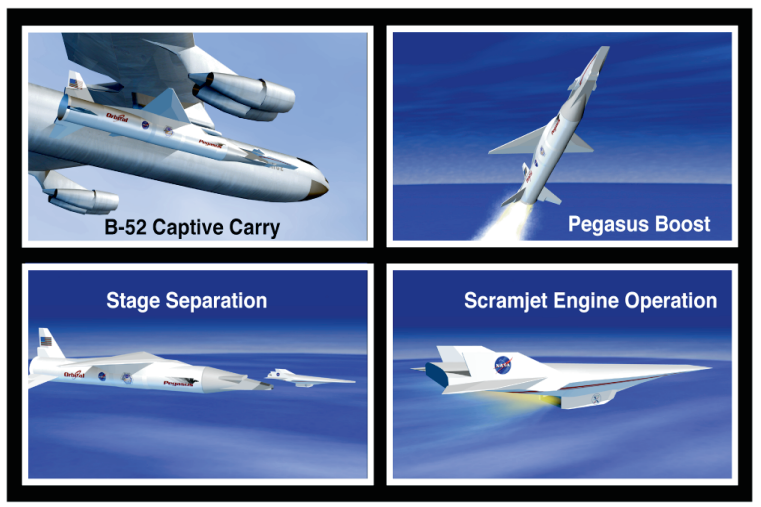

Figure 4. Key Mission Events for X-43A Flight

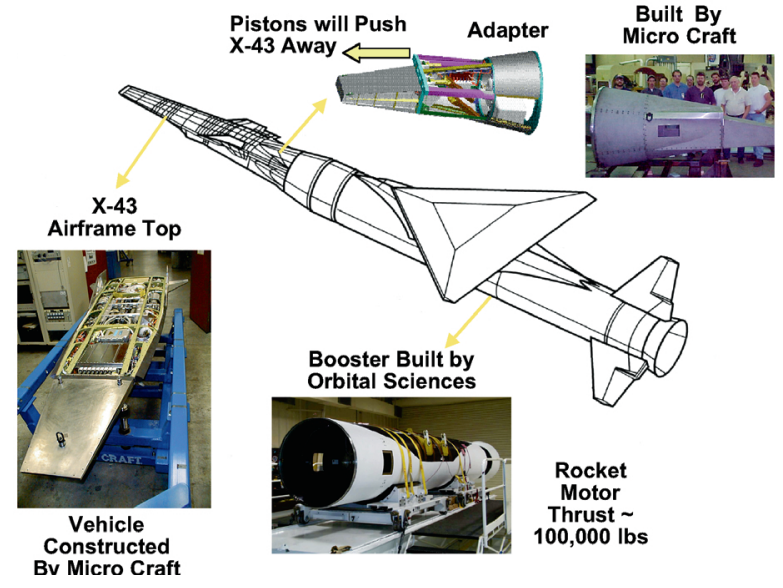

Figure 5. Baseline Configuration for Hyper-X 


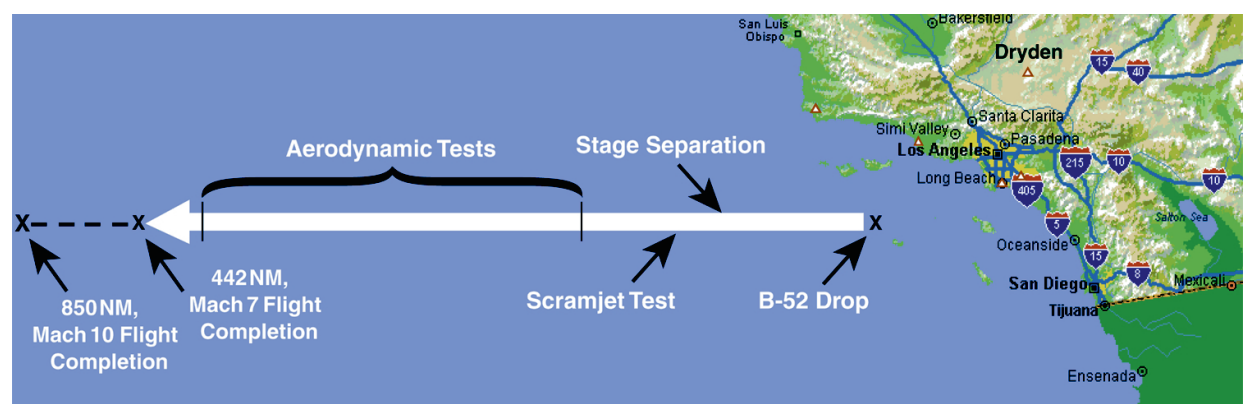

Figure 6. B-52 and X-43A Ground Track

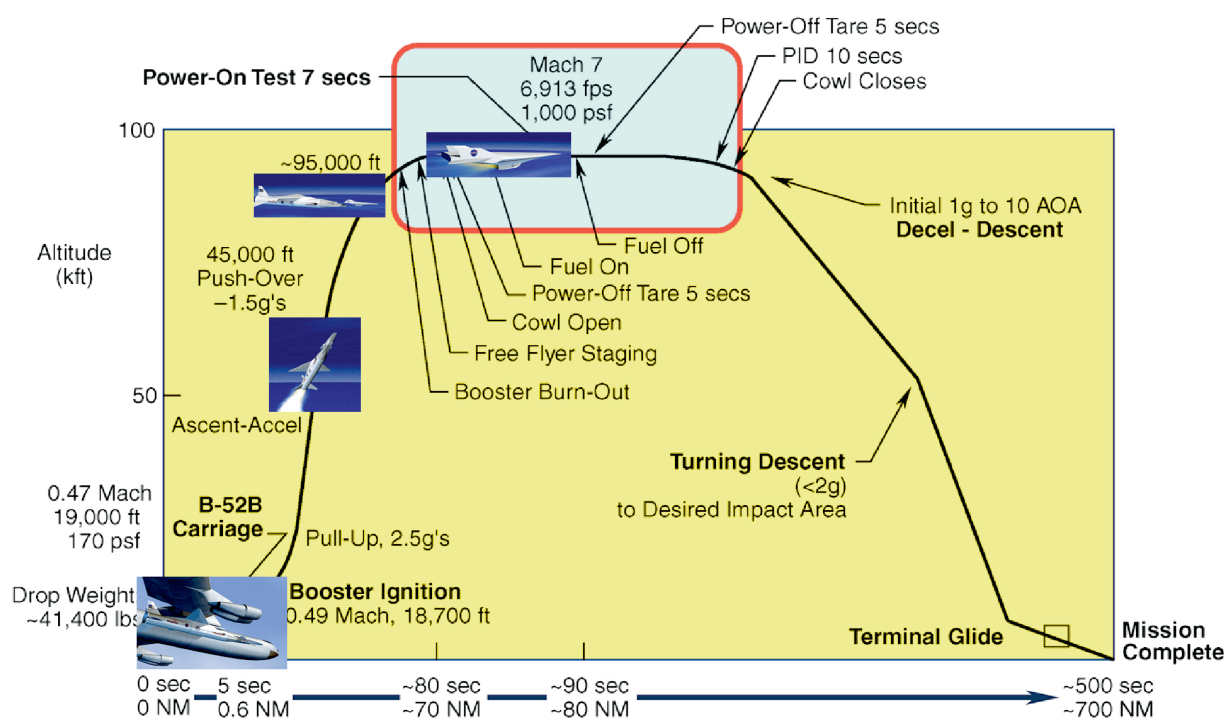

Figure 7. X-43A Flight Trajectory for Flight 1

\section{SYMBOLS AND ABBREVIATIONS}

\section{AFFTC Air Force Flight Test Center}

AFSRB Airworthiness \& Flight Safety Review Board

AOA Angle Of Attack

DFRC Dryden Flight Research Center

ECU Electronic Control Unit

ERB Engineering Review Board

FAS Fin Actuation System

fps feet per second

FRR Flight Readiness Review

HXLV Hyper-X Launch Vehicle

HXRV Hyper-X Research Vehicle

IMAR Integrated Mission Assurance Review

IPT Integrated Product Team

$\mathrm{I}_{\mathrm{sp}} \quad$ Specific Impulse

LaRC Langley Research Center

M Mach number

MIB Mishap Investigation Board

PA Peer Assessors

psf pounds per square foot

q dynamic pressure

RTF Return To Flight

\section{BACKGROUND}

The B-52 and X-43A ground track and trajectory for the pre-flight one nominal mission are shown in figures 6 and 7. For the June 2, 2001 first flight the NASA Dryden B-52B with the X-43A and Pegasus booster under its wing (figure 8) took off from Edwards Air Force Base and proceeded to the launch point within the Navy Western Test Range off the California coast. Flight to the launch point, drop of the booster stack, and ignition at 5 seconds after drop were all nominal. At about 13 seconds after drop the booster departed controlled flight at which time the

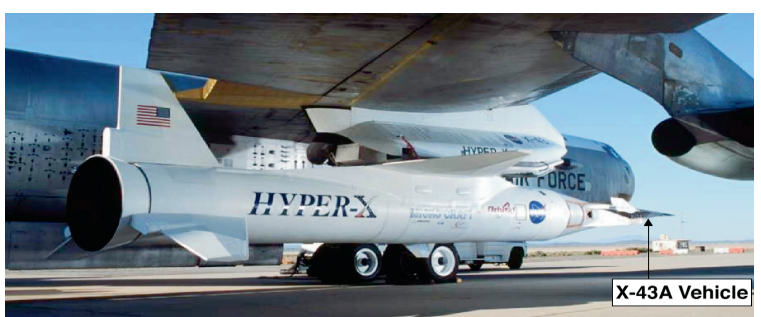

Figure 8. X-43A Booster Stack Under the Wing of DFRC B-52 
right fin broke off, followed within one second by the left fin and rudder. The wing broke off at 15 seconds and the booster data stream was lost at 21 seconds. At 48.5 seconds the Navy range safety officer initiated the flight termination system. The telemetry stream from the X-43A was lost at 77.5 seconds.

The X-43A Mishap Investigation Board was convened on June 5, 2001 and submitted its draft report March 8, 2002. The Board report identified inaccurate models (both Pegasus heritage and HXLV specific) resulting in a deficient control system design for the trajectory flown as the major contributor to the mishap. Return to Flight activities commenced in March, 2002 with development of a corrective action plan and an overall approach and roadmap for Return to Flight.

\section{RETURN TO FLIGHT ACTIVITIES}

The Return to Flight team used the MIB report and the corrective actions developed in response to the report as the starting point in the development of the plan of action for RTF activities. In addition, a thorough assessment of all phases of the X-43A flight was (B-52 carriage, boost, stage separation, research flight) conducted to identify risk areas which might benefit from further investigation. Additionally, workforce, facilities, and analysis tools requirements were identified and approaches for meeting them were developed. The RTF activities have been focused on reducing risk for all phases of the X-43 flight.

On the technical side of RTF activities, there have been extensive reviews of hardware and software designs and analysis, numerous wind tunnel tests, computational analyses and hardware testing for the refinement of existing mathematical models and systems design, and significant efforts expended at additional testing of both hardware and software. Analyses and simulations have been conducted with several independent means in order to check critical areas and to try to insure any errors would be caught.

Simulations have been run piecewise through the various phases of flight (boost, separation, research flight) as well as complete mission ("drop to splash"). In addition to analyses of the nominal trajectories, extensive Monte Carlo simulations have been run with newly developed uncertainty models of all appropriate parameters. These models emphasize conservatism to verify robustness to dispersions from nominal.

On the process side of activities the existing X-43 discipline IPT structure was strengthened. Strong communications and teamwork are emphasized. The IPT members develop an action plan containing all the RTF activities in that discipline area. Each action is assigned to a responsible individual and the action is regularly tracked until it is closed. The IPT also determines which activities require additional checks and how they are to be accomplished within the IPT. All actions and decisions by the IPTs are reviewed by the ERB before being implemented. All work by the IPTs and others are reviewed by a hierarchy of independent review teams (figure 9). The review teams range from Peer Assessors (subject matter experts not directly associated with the $\mathrm{X}-43 \mathrm{~A}$ project) who look in detail at specific items to much higher level reviewers who examine the project as a whole. The goal was to insure that there are different sets of eyes examining all aspects of the project at different, overlapping levels. The activities and decisions made by the project are documented at all levels.

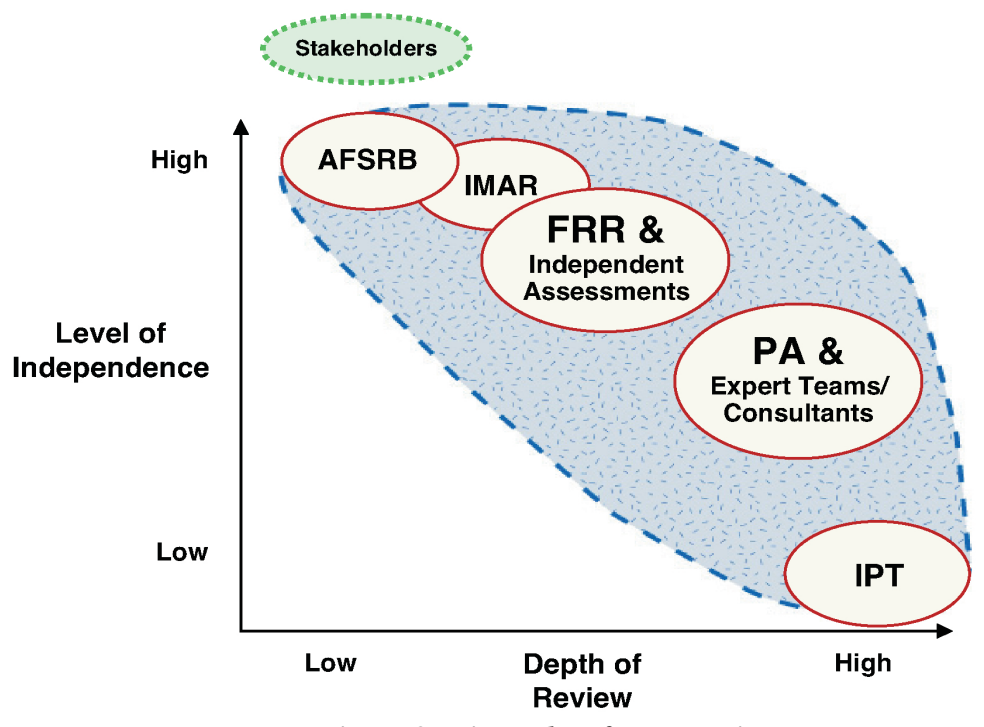

Figure 9. Hierarchy of RTF Reviews 


\section{RISK REDUCTION ACTIONS}

To reduce launch risk, higher fidelity models of the vehicle aerodynamics, the fin actuators, the vehicle structures, and the vehicle autopilot were developed. These addressed the major finding of the MIB that the first flight failure was a result of inaccurate modeling of the booster characteristics. To insure that the booster fin actuators did not stall as they did in the first flight new actuators with higher torque than the originals were developed (figure 10). This involved adding a second motor to the actuator in a torque summing arrangement, fabricating new gears to handle the increased capability, changing the actuator housing material from aluminum to stainless steel, adding two additional batteries for additional power, and redesigning the power and pre-driver boards in the electronic control unit for the actuators (figure 11). To

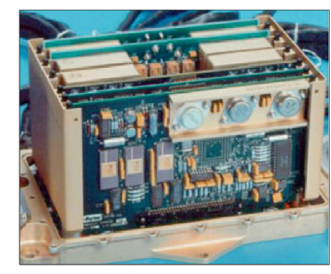

Electronic Control Unit (ECU)

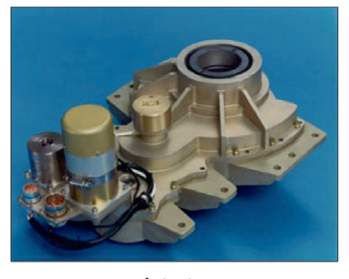

Actuator
- Objective: To increase the FAS hinge torque capability from $1850 \mathrm{ft}-\mathrm{lbs}$ to $3000+\mathrm{ft}-\mathrm{lbs}$

- Modifications:

- Add second motor in torque summing arrangement

- Fabricate new gears to handle higher loads

- Change housing material from aluminum to stainless steel

- Add two additional batteries

- Redesign the power and pre-driver boards in the ECU

- New FAS units have been built and tested-troubleshooting ECU

Figure 10. Booster Fin Actuation System further reduce risk for the boost about 3,350 lbs. of propellant has been removed from the booster (figure 12). For Mach 7 the standard first stage Pegasus motor had too much thrust to allow launching at the standard altitude of approximately 40,000 ft. To obtain the required conditions at the end of boost (Mach 7 at approximately 95,000 ft.) the first flight was launched at approximately $20,000 \mathrm{ft}$. This resulted in the booster seeing dynamic pressures at transonic conditions about twice that of a standard Pegasus flight. The predicted thrust profile of the off-loaded booster is shown in figure 13. With this off-loaded

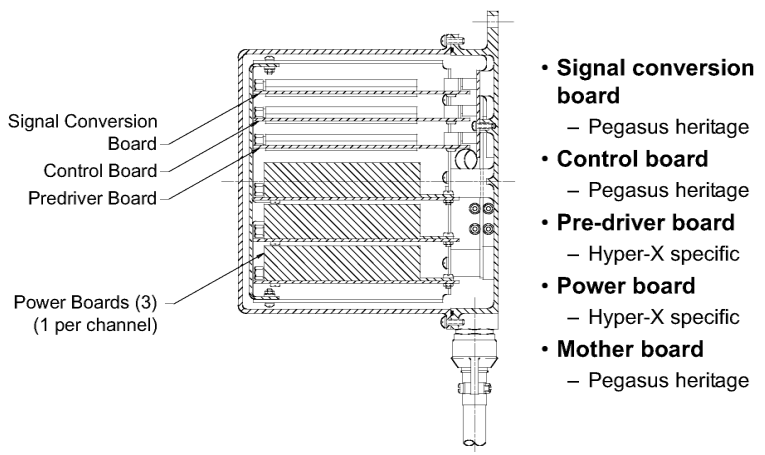

Figure 11. Booster FAS Electronic Control Unit Description

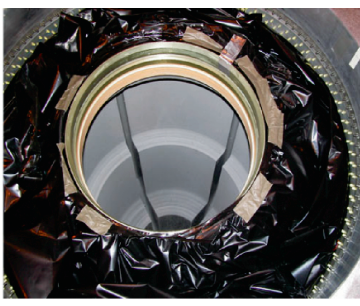

Halfway through Machining

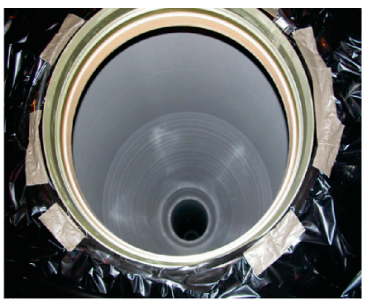

Machining Completed
Figure 12. Booster Propellant Off-Load

$$
\begin{aligned}
& \text { - Removing } \sim 3,345 \mathrm{lb} \text { of } \\
& \text { propellant }(12 \% \text { of prop. } \\
& \text { wt.) from fin slot region } \\
& \text { - Results in: } \\
& \text { - Reduced motor } \\
& \text { performance } \\
& \text { - Reduced stack } \\
& \text { weight } \\
& \text { - Throttle down } \\
& \text { - Longer burn time }
\end{aligned}
$$
- Reduced motor performance

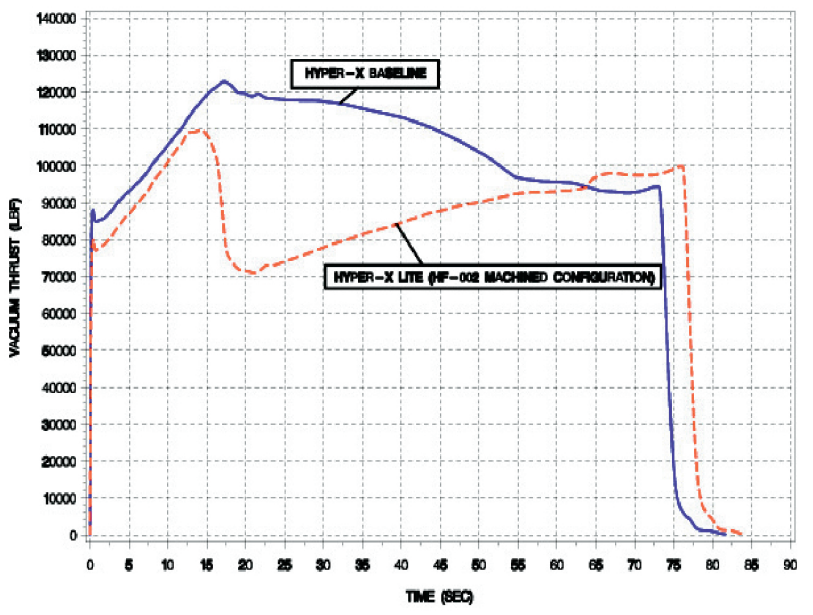

Offloaded motor performance predictions made by contractor were independently verified by government team

Figure 13. Predicted Thrust Profile of Off-Loaded Booster 


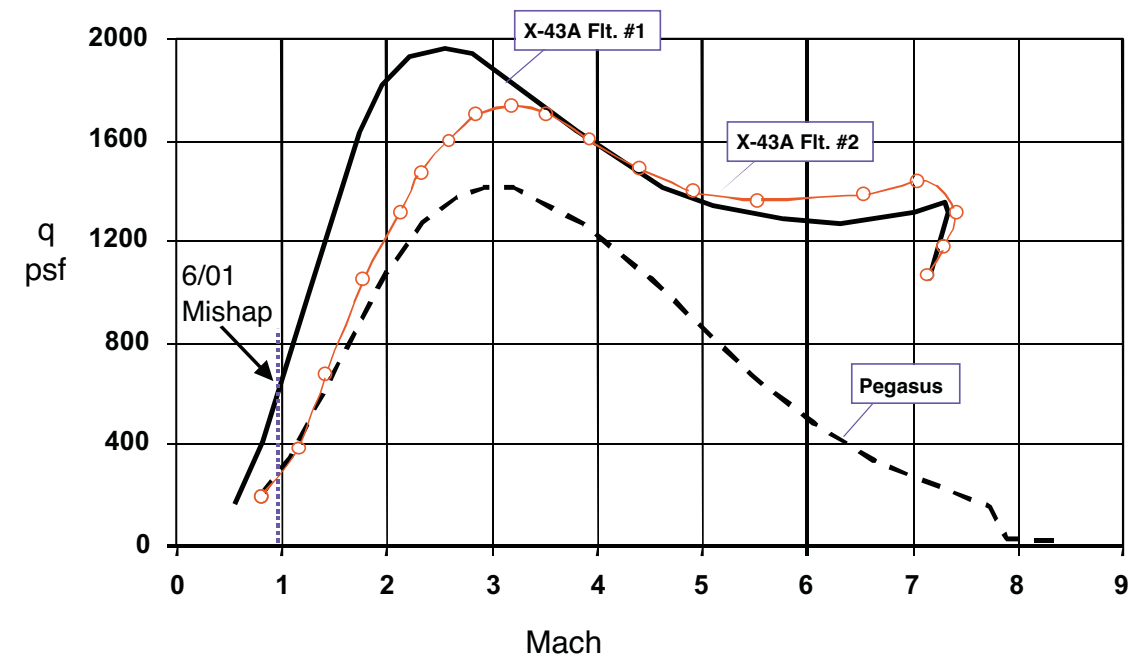

Figure 14. Dynamic Pressure Comparison Between First Flight and After Booster Off-Load

booster the launch can take place at the standard $40,000 \mathrm{ft}$. altitude and the booster will see significantly reduced dynamic pressure and loading (figure 14).

Risk reduction for the stage separation involved developing higher fidelity models of the separation using data from additional wind tunnel testing and CFD calculations. Also, the separation mechanism was further tested as part of the work in preparation for $\mathrm{X}-43 \mathrm{C}$. This additional data helped to further refine the modeling of the pyrotechnic piston push used to separate the vehicles. The research vehicle control laws were refined for the period of time of the separation so that the vehicle is more robust in its ability to handle potential upsets. Additionally, a totally new and separate simulation of the separation was developed to further verify the previous separation predictions. Time accurate, 3-D, moving body CFD calculations of the separation event were also done (figure 15) to improve confidence in the validity of the aerodynamic model.

There were also numerous activities associated with the research vehicle conducted to reduce risk to

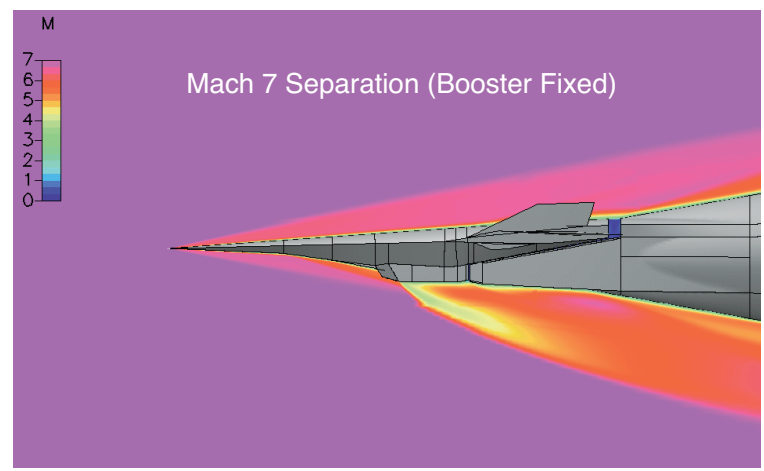

Figure 15. Time Accurate 3-D CFD Calculation of Stage Separation the vehicle and engine operation. Higher fidelity models of the vehicle and engine were developed. Additional wind tunnel testing of the engine indicated that a slight increase in angle of attack would result in greater thrust and a lower chance of flameout so this increase in angle of attack was incorporated in the flight software. An unstart control logic for the engine control system was developed and proved during wind tunnel testing. This new control logic has been incorporated in the flight engine controls. The wing control horns were redesigned for increased strength. It was observed from the separation video from the first flight that the vehicle left tail had rotated 180 degrees (figure 16). While the loads the vehicle saw during the booster departure were far above those expected from a nominal flight the control horns were strengthened to increase the structural margin. Aircraft-in-the-loop timing tests were conducted to document/eliminate data latency issues which had arisen during the evaluation of the data from the first flight.

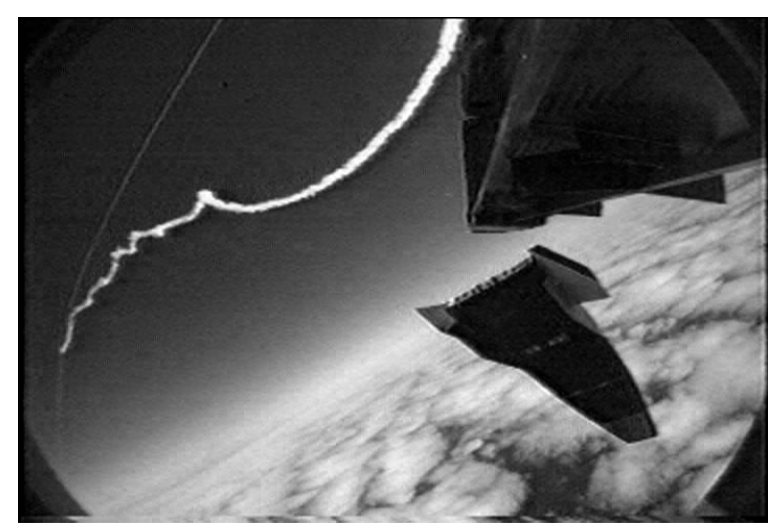

Figure 16. X-43A After Separation From Booster During First Flight 

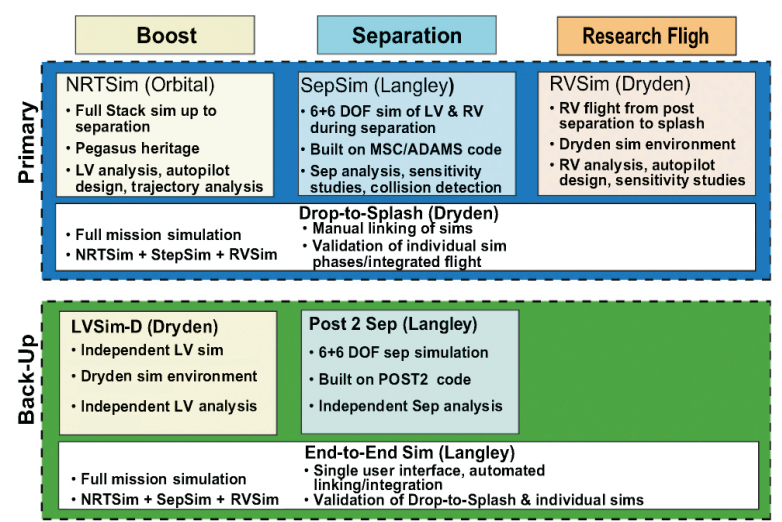

Figure 17. Various Flight Simulations Developed and Used During RTF to Assure Accuracy
The primary and back-up simulations used in evaluating the boost, separation, and research flight are depicted in figure 17. An example of the use of the back-up boost simulation is shown in figure 18. Shown are comparisons of Monte Carlo results for the boost between the Orbital (primary) and NASA (back-up) analysis. There is excellent agreement between the independent analyses and the Orbital results. Monte Carlo results from the latest stage separation analysis are shown in figure 19. Even with the use of conservative uncertainty models $97 \%$ of all cases result in a successful separation. Less than $1 \%$ of cases result in a re-contact with the adapter. Analysis of the engine-on vehicle stability margins with the latest, conserva-

Lower rows of numbers correspond to OSC Baseline Trajectory 2.0 Statistics

\begin{tabular}{|l|l|l|l|l|}
\hline Separation Parameter & Mean & Max & Min & Standard Deviation \\
\hline Time Burn-out to Sep (sec) & 12.1172 & 14.84 & 8.96 & 0.983614 \\
& 12.23 & 15.44 & 9.52 & 1.01 \\
\hline Mach & 7.04085 & 7.42662 & 6.61281 & 0.11957 \\
& 7.035 & 7.441 & 6.66 & 0.127 \\
\hline Dynamic Pressure (psf) & 1049.91 & 1179.01 & 967.623 & 30.1392 \\
& 1048 & 1135 & 951 & 29 \\
\hline Flight Path Angle (deg) & 2.12783 & 3.09844 & 0.487972 & 0.341039 \\
& 2.12 & 2.95 & 0.098 & 0.32 \\
\hline Angle of Attack (deg) & -0.0885966 & 0.630392 & -0.719544 & 0.214806 \\
& -0.1 & 0.56 & -0.73 & 0.22 \\
\hline Angle of Sideslip (deg) & -0.00436411 & 0.843139 & -0.953169 & 0.276357 \\
& 0.02 & 1.02 & -0.86 & 0.28 \\
\hline Bank Angle (deg) & 0.127211 & 2.21125 & -2.08368 & 0.6641 \\
& 0.08 & 1.5 & -1.74 & 0.57 \\
\hline Roll Rate (deg/sec) & 0.0116867 & 1.99444 & -1.7962 & 0.51148 \\
& 0.01 & 1.71 & -1.43 & 0.36 \\
\hline Pitch Rate (deg/sec) & -0.261446 & -0.123094 & -0.409233 & 0.0369786 \\
& -0.26 & -0.17 & -0.36 & 0.02 \\
\hline Yaw Rate (deg/sec) & 0.00373579 & 0.252297 & -0.210815 & 0.0543962 \\
& 0.00 & 0.12 & -0.16 & 0.04 \\
\hline
\end{tabular}

- Nominal trajectory/autopilot design confirmed by independent analysis

- Uncertainty analysis (system robustness) confirmed with excellent agreement of independent Monte Carlo results with corresponding Orbital statistics

Figure 18. Comparison of Booster Baseline Trajectory Statistics with those from Independent Simulation

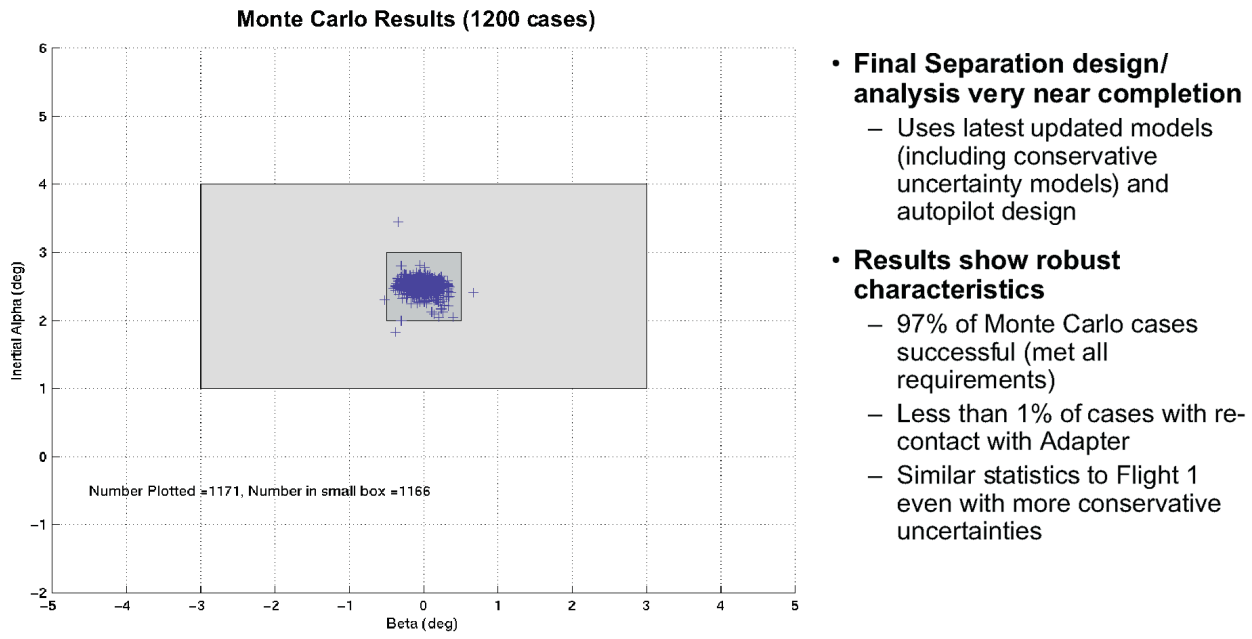

Figure 19. Results from Final Separation Analysis 
Mach 7.0, Engine On Vehicle Stability Margins
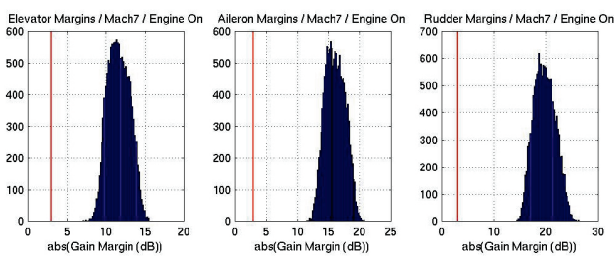

- Final RV design/analysis essentially complete

- Uses latest updated models (including conservative uncertainty models) and autopilot design
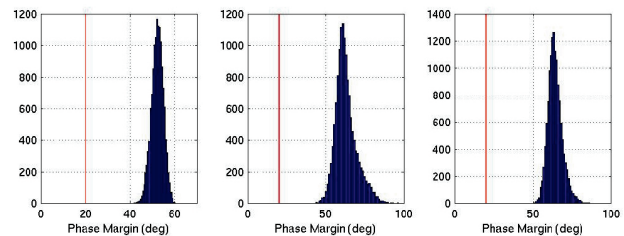

- Results show robust characteristics

- Linear stability margins well above requirements

- Confirmed by nonlinear Monte Carlo results

Figure 20. Engine on Vehicle Stability Margins from Final Analysis
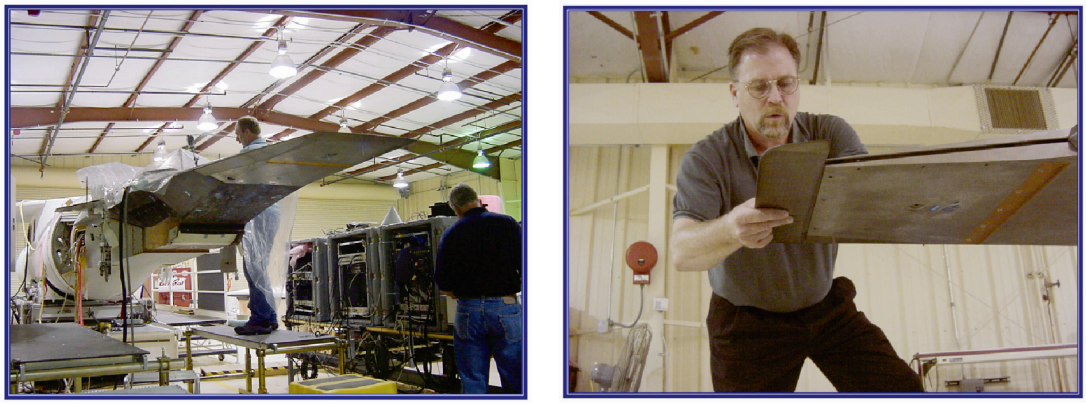

Figure 21. Full Stack Mate-July 2003
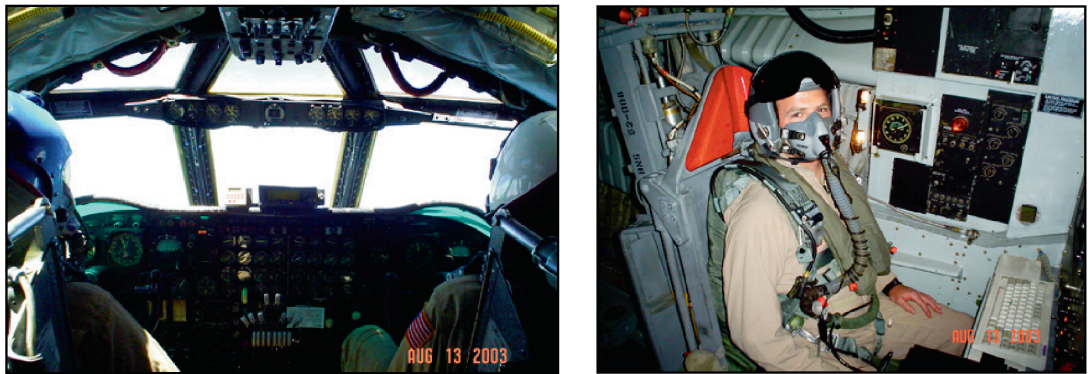

- B-52 Range flight conducted on $8 / 13 / 03$

- Checked all B-52 X-43A systems (monitor stations, power systems, pylon adapter, etc.)

- Checked all range assets (Dryden, AFFTC, Vandenburg, Pt. Mugu) (data systems, radar tracking, comm links, etc.)

- Verified B-52 flight plan (waypoints, timing, etc.)

- Aircraft and control room crew training

Figure 22. B-52 Range Flight-August 2003

tive uncertainty models show robust characteristics with linear stability margins well above requirements (figure 20).

The nitrogen system in the booster adapter was also modified. During the first flight debris from a pyrotechnic valve caused a regulator in the nitrogen system used for purge and cooling water pressurization to fail. While it was determined that there was sufficient conservatism in the design so that there would have been enough nitrogen for a successful engine test, a filter has been added to the system to eliminate the possible debris problem.

\section{RECENT ACTIVITIES}

The mating of the launch vehicle, booster adapter, and research vehicle occurred in early July (figure 21). A flight of the B-52 was conducted on August 13, 2003 (figure 22). This allowed the check-out of all 
B-52 systems and range assets as well as verifying the flight plan and providing aircraft and control room crew training. A check-out mating of the $\mathrm{X}-43 \mathrm{~A}$ stack with the B-52 was conducted in September of 2003 (figure 23). The flight readiness review was conducted in September as well. A "hanger" radiation test has been conducted to insure no EMI issues exist. At the time this paper is written a captive carry flight with the booster stack under the wing of the B-52 to rehearse the launch is scheduled for mid-December; the Airworthiness and Flight Safety Review Board meeting is scheduled for the early January time frame; and the flight attempt is scheduled for late January/February of 2004.

\section{CONCLUDING REMARKS}

This paper has discussed highlights of the return to flight activities for the X-43A scramjet flight experiment after a first, unsuccessful flight attempt in June, 2001. Significant work has been done to reduce risk for all segments of the flight. The next flight attempt is currently scheduled for early in 2004.

\section{REFERENCES}

1. Rausch, V.L.; McClinton, C.R.; and Crawford, J.L.: Hyper-X: Flight Validation of Hypersonic Airbreathing Technology. ISABE 97-7024, Sep. 7-12, 1997, Chattanooga, TN.

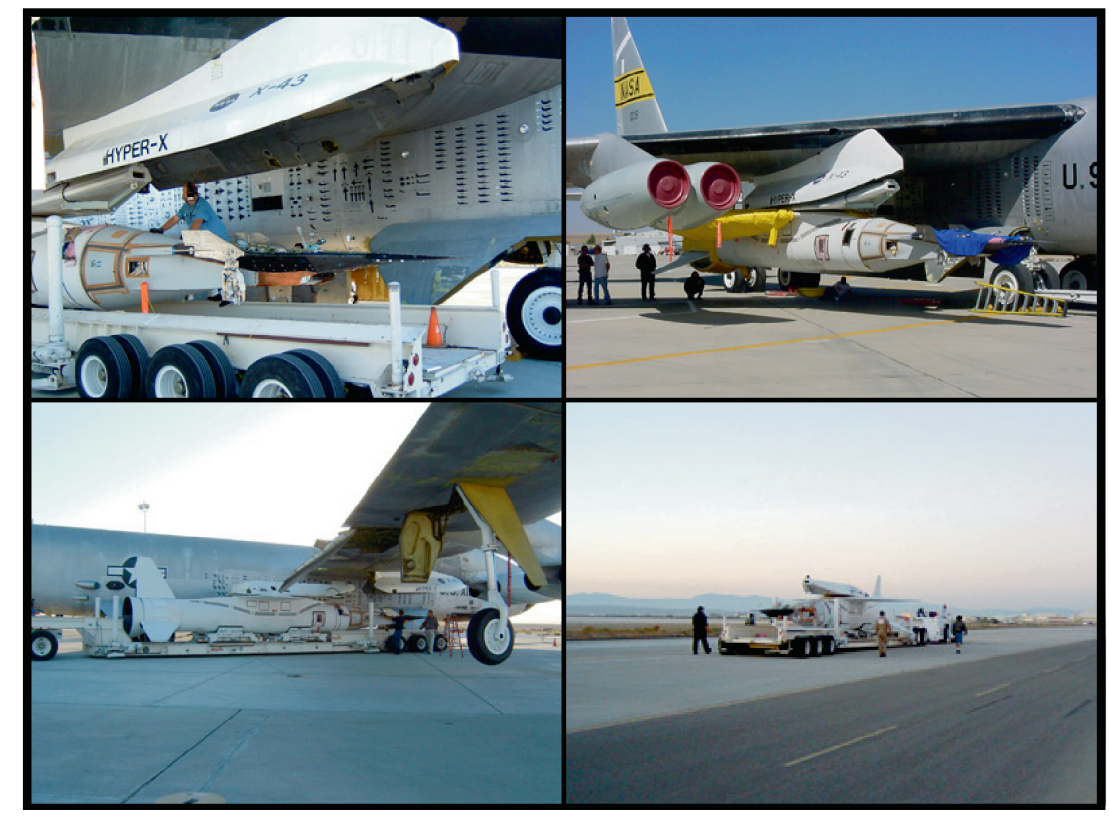

Figure 23. X-43A Stack Mate with B-52 